Chair for Management Science and Energy Economics University of Duisburg-Essen

EWL Working Paper No. [03/14]

\title{
SUPPORT MECHANISMS FOR RENEWABLES: HOW RISK EXPO- SURE INFLUENCES INVESTMENT INCENTIVES
}

by

Lena Kitzing

and

Christoph Weber

15.08.2014 


\title{
Support mechanisms for renewables: How risk exposure influences invest- ment incentives
}

\author{
by Lena Kitzing, Christoph Weber
}

\begin{abstract}
We analyse quantitatively how risk exposure from different support mechanisms, such as feed-in tariffs and premiums, can influence the investment incentives for private investors. We develop a net cash flow approach that takes systematic and unsystematic risks into account through cost of capital and the Capital Asset Pricing Model as well as through active liquidity management. Applying the model to a specific case, a German offshore wind park, we find that the support levels required to give adequate investment incentives are for a feed-in tariff scheme approximately 5-7\% lower than for a feed-in premium scheme. The effect of differences in risk exposure from the support schemes is significant and cannot be neglected in policy making, especially when deciding between support instruments or when determining adequate support levels.
\end{abstract}

Keywords : investment risk, support policies, unsystematic risk, liquidity management, offshore wind, feed-in tariffs

LENA KITZING

DTU Management Engineering

Energy Systems Analysis

Technical University of Denmark

Riso Campus

P.O. Box 49, DK-4000 Roskilde

\section{CHRISTOPH WEBER}

Chair for Management Science and Energy Economics, University of Duisburg-Essen (Campus Essen) Universitätsstr. 11, 45117 Essen ++49 - (0)2 01 / 183-2399 www.ewl.wiwi.uni-due.de christoph.weber@uni-due.de

The authors are solely responsible for the contents which do not necessarily represent the opinion of the Chair for Management Sciences and Energy Economics. 


\title{
Support mechanisms for renewables: How risk exposure influences investment incentives
}

\author{
Lena Kitzing ${ }^{1, *}$, Christoph Weber ${ }^{2}$ \\ ${ }^{1}$ Technical University of Denmark, DTU Management Engineering, Energy Systems Analysis, Risø Campus, \\ P.O. Box 49, DK-4000 Roskilde, Denmark \\ ${ }^{2}$ University of Duisburg-Essen, Institute for Business and Economic Studies, Management Science and \\ Energy Economics, Campus Essen, Universittsstrasse 12, 45117 Essen, Germany
}

\begin{abstract}
We analyse quantitatively how risk exposure from different support mechanisms, such as feed-in tariffs and premiums, can influence the investment incentives for private investors. We develop a net cash flow approach that takes systematic and unsystematic risks into account through cost of capital and the Capital Asset Pricing Model as well as through active liquidity management. Applying the model to a specific case, a German offshore wind park, we find that the support levels required to give adequate investment incentives are for a feed-in tariff scheme approximately 5-7\% lower than for a feed-in premium scheme. The effect of differences in risk exposure from the support schemes is significant and cannot be neglected in policy making, especially when deciding between support instruments or when determining adequate support levels.
\end{abstract}

Keywords: Investment risk; Support policies; Unsystematic risk; Liquidity management; Offshore wind; Feed-in tariffs

\section{INTRODUCTION}

Electricity generation from renewable energy sources (RES-E) is supported in many countries around the world. In the European Union, every Member State has established a dedicated policy programme for financial support of RES-E (Kitzing et al. 2012). Ever since the first support schemes were designed by policy makers some decades ago, there is an ongoing debate about which policy instruments and which design options are most suitable for an effective and efficient deployment of renewable energies.

This paper contributes to this debate by exploring risk implications of policy instruments and analysing the impact of policy choices on incentives for private investors. This perspective is especially relevant in liberalised markets. Here, policy making must ensure that adequate incentives are given to private investors so that specific RES-E targets can be achieved. To design effective and efficient policies, policy makers must look beyond costs and consider all aspects that are of concern for private investors, including effects on cost of capital and other risk implications (see also Gross et al. 2010). With such insight, policy makers are able to make informed decisions about required support levels and to evaluate the consequences of switching from one policy instrument to another.

In Europe, fixed feed-in tariffs (FIT) are the dominant policy instrument applied for the support of RES-E (Kitzing et al. 2012). With an increasing share of variable RES-E in the system and an increasing pressure to improve market integration of RES-E, many countries have now started to re-evaluate the use of traditional FIT schemes. Some have already implemented alternatives, mostly in form of feed-in premiums (FIP) (Kitzing et al. 2012). A counter-argument frequently put forward against FIP is that this instrument exposes RES-E investors to higher risk (see Klessmann et al. 2008). In light of the ongoing policy trend in Europe and the related debate, this paper develops a general approach to analyse implications of choosing support schemes that expose investors to higher market risks than before. We then use the developed approach to analyse the switching from a FIT to a FIP scheme and quantify the consequences regarding investment attractiveness and required support payments for the case of an offshore wind investment in Germany.

The developed model aims at a theoretically consistent approach, drawing from different aspects of financial theory, along with an empirically sound parametrisation. The standard model for dealing with risk in investment analysis is the Capital Asset Pricing Model (CAPM), developed by Sharpe (1964), Lintner (1965), and Mossin (1966), which determines systematic risk and cost of capital based on the correlation of asset return with the market. We consider systematic risk based on the CAPM approach. In addition to that, we also consider unsystematic risk. We diverge from the standard approach here by assuming that investors may accrue cost from avoiding financial distress. In this, we draw from the approach developed by Schober et al. (2014).

\footnotetext{
*corresponding author,+45 46775188, 1kit@dtu.dk.
} 
The contributions of this paper are threefold: 1) We expand the framework of Schober et al. (2014), who assessed the impact of unsystematic risk via liquidity management for a single year, by developing a multi-year approach; 2) We apply the framework to a new area, namely investments in renewable energy projects under different support schemes; 3) We quantify the consequences of different risk exposures for a concrete case, an offshore wind park in Germany.

The remainder of the paper is structured as follows. In Section 2, we describe the background for our analysis, including the relation to financial theory, the general DCF approach and the relevant support instruments. In Section 3 , we introduce our methodology, including the model structure, the modelling of stochastic processes, the modelling of liquidity management, and the beta analysis for the CAPM. In Section 4, we apply the model to a specific case, namely a German offshore wind park in the Baltic Sea. We discuss the results in Section 5 and conclude with Section 6

\section{GENERAL CONSIDERATIONS: INVESTMENT RISK}

\subsection{Standard financial theory and systematic vs. unsystematic risk}

A basic assumption of standard financial theory and portfolio selection theory is that risk and return and the only - and equally important - factors to consider in investment appraisal (Markowitz 1952). Later, Sharpe (1964) and Lintner (1965) showed that firms should only be concerned with systematic risks when considering investment in new assets. This is, because it is assumed that perfect portfolio diversification can be obtained at shareholder level without transaction costs. This also implies that a firm should not undertake costly measures to avoid bankruptcy as, in perfect markets without transaction costs, old firms can go bankrupt and new firms can be established immediately at no loss. In reality, however, costs of bankruptcy can be substantial and irreversible (Bris et al. 2006): They can include loss of market share, inefficient asset sales, foregone investment opportunities, and more. Firms are thus often willing to undertake costly measures to avoid economic and financial distress (Davydenko. 2012).

In newer developments of financial analysis, also risks other than systematic market risk are being acknowledged. Further risk factors are incorporated into the analysis, e.g. in the three-factor model by Fama and French (1993), with the argument of market imperfections (and consequential diversification constraints), as well as transaction costs that make such types of risk costly. The choice of model can have significant implications on the valuation of investment projects. Empirical studies have found that required returns on equity may differ by $2 \%$ and more between the CAPM and the Fama-French-Model (Fama and French, 1997, Schaeffler and Weber. 2013).

Also for renewable assets, we expect that both systematic and unsystematic risks are relevant for investment decisions, because of transaction costs and irreversibility effects. In the presence of transaction costs, the generally agreed assumption of financial theory that investors are risk-averse (see Arrow. 1965) predicts that investors are willing to take action against risk exposure, by implementing safety measures - even if costly. We acknowledge that failures (e.g. bankruptcy) are costly to investors, and incorporate them into the analysis.

Our model is based on a net cash flow approach with risk modelling at two levels: 1) systematic risk, which stems from market risks and influences the cost of capital; and 2) unsystematic risk, which affects the required capital basis for an investment. More specifically, we assume that firms use liquidity reserves to mitigate their exposure to risk of financial distress. A greater variation in profit will generally require higher liquidity reserves. We thus expect that a support mechanism which mitigates variation in profits the most leads to the lowest required liquidity reserves and thus highest expected returns.

A challenge with unsystematic risks is, however, that they are mostly in-transparent and specific for an individual firm. We therefore revert to an application case showing the concrete effects in a specific setting.

\subsection{Discounted cash flow evaluation of an investment}

The standard method for evaluating investments is the discounted cash flow (DCF) approach (see e.g. Brealey and Myers. 2003). In this approach, all positive and negative cash flows related to the respective investment project are estimated, discounted with the applicable rate for the cost of capital, and summed up, as shown in Equation (1):

$$
N P V=-I_{0}+\sum_{t=1}^{T} \frac{R_{t}-C_{t}}{(1+r)^{t}}
$$


where $I_{0}$ are the investment costs, $R_{t}$ are the revenues, $C_{t}$ are the operational costs, $r$ is the discount rate (cost of capital), and $T$ is the project lifetime.

If the resulting net present value (NPV) of a project is positive, then the investment should be undertaken. Since many of the different elements contained in the future positive and negative cash flows are not known with exactitude, they have to be estimated. To account for the uncertainty, many investors include probability distributions of underlying elements in their assessment. This is done by e.g. creating different scenarios or making Monte Carlo simulations.

In principle, all three basic cash flows, namely revenues $R_{t}$, operational cost $C_{t}$, and investment cost $I_{0}$, can contain uncertainties. We simplify subsequently by assuming that at the time of investment decision, $I_{0}$ and $C_{t}$ are known and fixed. This may e.g. be achieved through fixed price contracts. Future revenue streams $R_{t}$ are however uncertain and can cause variations in the returns from the project, which induces risk.

Traditional DCF analysis is based solely on standard financial theory and the assumptions underlying the CAPM in which only systematic risk is relevant. Systematic risks are exclusively dealt with through the cost of capital $r$. We have argued above that also unsystematic risks should be accounted for in our type of analysis. We do this by considering the prevention of bankruptcy through liquidity management.

\subsection{Liquidity management: cash reserves in firms}

When considering unsystematic risks in form of risk of default or bankruptcy in a firm, one should distinguish between economic and financial distress. Economic distress occurs at low market asset values relative to debt and causes insolvency. Financial distress occurs at low cash reserves relative to current liabilities and leads to illiquidity. Usually, a firm defaults because of both factors, but this has not necessarily to be the case. Davydenko (2012) shows that $13 \%$ of defaulting firms in his sample were insolvent but still liquid, and $10 \%$ of defaulting firms were illiquid but still solvent. In our theoretical model, we focus on the indicator of financial distress (and firms avoiding illiquidity), acknowledging the simplification made. Moreover, we simplify by assuming that risk of financial distress represents all unsystematic risks in a firm. Knowing that there might be additional sources of costly unsystematic risk, our results can only establish the lower boundary for such costs. This approach corresponds to the one taken by Schober et al. (2014).

One way to deal with risk of financial distress is liquidity management. Liquidity management can take the form of either expenses for costly hedging (in order to reduce the risk of low revenues for the firm) or provision of an additional capital buffer in the firm (Schober et al. 2014). We understand liquidity management as the decision to upholding an optimized level of capital buffer within the firm to prevent defaulting, i.e. the going concern in possible illiquid states. A firm has several options to create a capital buffer: 1) secure bank lines of credit; 2) establish sufficient cash reserve in the beginning of a risky project; 3) raise required capital in the short term from shareholders (through retained earnings or equity injections).

As discussed by Flannery and Lockhart (2009), uncertainty about access to funds in the future (including from banks) might lead to excess cash holdings in a firm. Bates et al. (2009) give an overview of the literature's theories of holding excess cash in firms and show empirically that excess cash holdings in firms are common. Thus, we focus on cash reserves and capital from shareholders in this analysis (and not bank lines of credit). Because of the time-value of money and tax effects of cash holdings, a firm will however consider it optimal to build up cash reserves as late as possible. This corresponds to the conclusions of Acharya et al. (2007), who find that constrained firms are more likely to save cash out of cash flows. Therefore, we focus on the third of the above mentioned options, in which firms raise capital as late as possible either through retained earnings (i.e. by saving of incoming cash flows during operations) or, whenever necessary, by additional equity injections. This implies that a firm will strive to keep the liquidity reserve in any year as low as possible - just at the level needed to avoid financial distress in the next period with sufficient probability. It should be noted that liquidity management through cash reserves in the firm can at best decrease the risk of financial distress to a desired level, but can never eliminate it completely.

\subsection{Support schemes and investment risk}

Several different policy instruments can be used to provide financial support for renewable energy projects. These span from investment grants over tax breaks to generation-based support. The latter type is dominant in Europe (Kitzing et al. 2012). Here, one can distinguish between instruments that expose renewable producers to market price risks and those that eliminate or at least reduce market price risks. During the early implementations of renewable support, mostly those instruments were applied that shield renewable producers from market price signals and thus also market risks (Kitzing et al. 2012). These are for example fixed feed-in tariffs, where renewable producers are guaranteed a fixed price for a certain period (e.g. 20 years). 
Equation (2) illustrates the revenue flows under a feed-in tariff scheme:

$$
R_{t}^{F I T}=q_{t} F I T
$$

where $q_{t}$ is the renewable energy production volume per time period and FIT is the long-term guaranteed tariff level. Uncertainty stems here solely from the unknown production volume, which depends on the available renewable resources in time period $t$.

More recently, other instruments like quota systems with tradable green certificates or feed-in premiums are increasingly applied in Europe (Kitzing et al. 2012). In these schemes, support is paid out as market add-on. This means that renewable producers need to sell their production on the power market and are exposed to its risks. We focus here on feed-in premiums, under which revenues are determined as in Equation (3):

$$
R_{t}^{F I P}=q_{t}\left(S_{t}+F I P\right)
$$

where $q_{t}$ is the renewable energy production volume in period $t, S_{t}$ is the power price, and $F I P$ is the long-term guaranteed premium level. Uncertainty stems here from both the unknown production volume and the unknown market price.

\section{METHODOLOGY}

\subsection{Model structure}

We develop a multi-year cash flow model that estimates the investment incentives for a wind energy investor under different risk exposures, and that incorporates dynamic liquidity management. The purpose of the model is to determine a Shareholder Value (SHV) after liquidity management, which then can be used to compare the attractiveness of investment under different scenarios. For transparency reasons, we model a firm that has a single activity: the investment project throughout the lifetime of the project. This is also similar to creating a special purpose vehicle for a project. We thus assume that the SHV of this project/firm is the key determinant for the investment decision. Using the SHV, we can also derive the minimum required support level for the specific project, by assuming that the investment threshold is given by an ex-ante expected SHV of at least zero. Based on these two indicators (SHV and required support levels), comparisons between different support scheme designs can be made.

Figure 1 illustrates the model structure. The model consists of several parts: a power price model, a wind production model, the beta analysis (estimating cost of capital), and the cash flow model (divided into cash flows before liquidity management and after). Two nested module functions undertake the required Monte Carlo simulations.

In the following sections, the different components of the model are explained in detail. Since we aim at deriving a multiyear investment assessment, we focus on the stochastic characteristics of annual quantities and prices, which in turn represent aggregates of shorter-term (e.g. hourly) values.

\subsection{Power price model}

For modelling the annual average power prices, we use the two-factor model developed by Schwartz and Smith (2000). This two-factor model consists of a long term process reflecting the uncertainty in the equilibrium price and a short term process reflecting stochastic shorter term deviations from the equilibrium price. The logarithm of the overall power price $S_{t}$ is obtained as the sum of the two stochastic components:

$$
\ln \left(S_{t}\right)=\xi_{t}+\chi_{t}
$$

The long term process $\xi_{t}$ expresses fundamental changes in the equilibrium level that are expected to persist, and reflects the natural logarithm of the long-run equilibrium level $\bar{S}_{t}$. Changes in this long-run equilibrium level may e.g. be related to changing fuel prices or modifications in the $\mathrm{CO}_{2}$ regime. The developments over the last decade suggest that these changes are hardly predictable and that also in the future, substantial uncertainty will persist. The long term process then follows an 


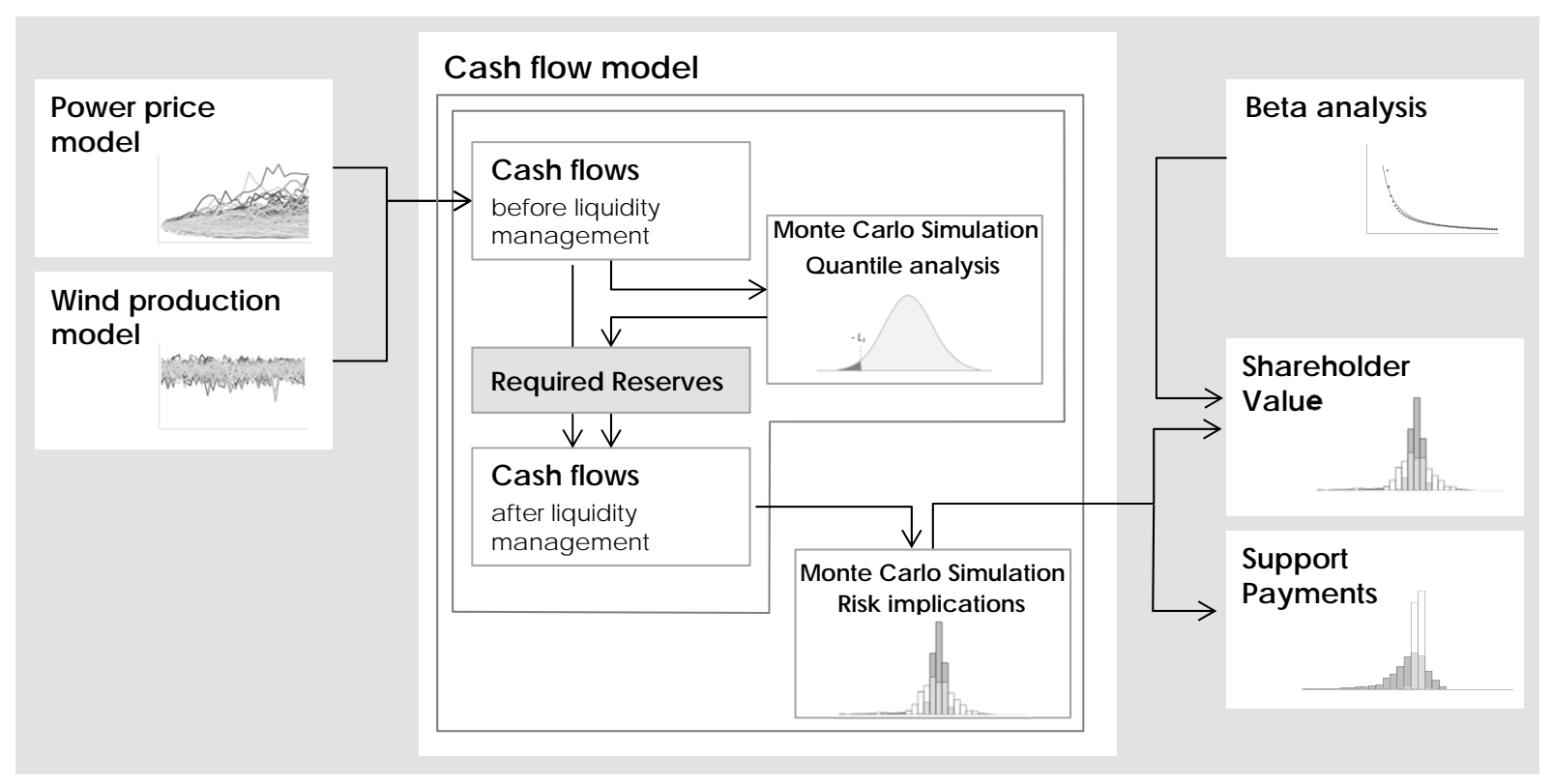

Fig. 1: Model structure

arithmetic Brownian motion:

$$
d \xi_{t}=\mu_{\xi} d t+\sigma_{\xi} d z_{\xi}
$$

where $\xi_{t}$ has drift $\mu_{\xi}$ and volatility $\sigma_{\xi}$. This corresponds, according to It's Lemma, to

$$
d \bar{S}_{t}=\bar{S}_{t}\left(\mu_{\xi}+\frac{1}{2} \sigma_{\xi}^{2}\right) d t+\bar{S}_{t} \sigma_{\xi} d z_{\xi} .
$$

The long term process can be exactly discretised using an Euler scheme (Davis, 2012) to:

$$
\xi_{t+\Delta t}=\xi_{t}+\mu_{\xi} \Delta t+\sigma_{\xi} \sqrt{\Delta t} \varepsilon_{t},
$$

where $\varepsilon_{t}$ is a random element with $\varepsilon_{t} \sim N(0,1)$.

The short term process $\chi_{t}$ expresses the mean reverting relation between the current price and the currently expected long term equilibrium:

$$
\chi_{t}=\ln \left(\frac{S_{t}}{\overline{S_{t}}}\right)=\ln \left(S_{t}\right)-\xi_{t} .
$$

Its deviations are assumed to revert to zero following an Ornstein-Uhlenbeck process:

$$
d \chi_{t}=-\kappa \chi_{t} d t+\sigma_{\chi} d z_{\chi}
$$

where $\chi_{t}$ has volatility $\sigma_{\chi}$ and mean reversion coefficient $\kappa$.

The discretisation necessary for simulation is according to Phillips $1972[1$.

$$
\chi_{t+\Delta t}=\chi_{t} e^{-\kappa \Delta t}+\sigma_{\chi} \sqrt{\frac{1-e^{-2 \kappa \Delta t}}{2 \kappa}} \bar{\omega}_{t},
$$

where $\bar{\omega}_{t}$ is a random element with $\bar{\omega}_{t} \sim N\left(\rho_{\chi \xi} \varepsilon_{t}, 1-\rho_{\chi \xi}^{2}\right)$ and $\rho_{\chi \xi} \in[-1,1]$ represents the correlation of $d z_{\xi}$ and $d z_{\chi}$.

${ }^{1}$ and not - as often done - using an Euler scheme, see Davis (2012) 


\subsection{Wind power production model}

Wind production is modelled in a somewhat simplified setting by assuming that the wind production of one period is unrelated to previous or subsequent periods. We deem this approach appropriate when the model calculations are based on relatively large time steps $t$, such as monthly or yearly periods. Thus focusing on time-uncorrelated distributions, several studies emphasise the appropriateness of Weibull distributions. These are deemed most appropriate for estimating wind speeds and also wind energy production, see e.g. Villanueva and Feijóo (2010) or Carta and Velázquez (2011). We thus use a Weibull distribution, directly on the wind energy production. For the implementation in simulation, we use the quantile inverse cumulative distribution function:

$$
q_{t}=P \lambda\left(-\ln \left(1-\varepsilon_{t}\right)\right)^{\frac{1}{k}}
$$

where $q_{t}$ is the stochastic wind power production in period $t, P$ is the average expected wind power production from the project, $\lambda$ is the scale parameter of the Weibull distribution, $k$ is the shape parameter of the Weibull distribution, and $0<\varepsilon_{t}<1$ is a uniformly distributed random variable, corresponding to the quantile of the production distribution function.

\subsection{Cash flow model: before and after liquidity management}

As mentioned above, we focus on the shareholder values and thus use the free cash flow available for shareholders $F C F E_{t}$ as basis of the evaluation. We denote the sum of all discounted FCFE after liquidity management as the Shareholder Value (SHV). This indicator serves as the basis for comparing the investment incentives between different cases.

At time of investment $(t=0), F C F E_{0}$ consists of cash flows from investment and financing activities. Total capital required at project investment is: $\Omega_{0}=I_{0}+L_{0}$, where $I_{0}$ is the direct investment cost and $L_{0}$ is the liquidity reserve that the firm has chosen to establish from the beginning of the project (if any).

We calculate the free cash flow available for shareholders before liquidity management for each year $t=1 \ldots T$ as:

$$
F C F E_{t}=R_{t}-C_{t}-\theta_{t}-T_{t}+D_{t}
$$

where $R_{t}$ are the revenues, $C_{t}$ are the operation and maintenance cost, $\theta_{t}$ are the interests paid for interest-bearing debt, $T_{t}$ are the payable taxes (based on revenues, operational costs depreciation and interests), and $D_{t}$ are the debt injections (if positive) or the debt repayments (if negative).

The revenues $R_{t}$ depend on the production volume, on the achieved market price, and on the payments from the support scheme. The revenues under the two analysed support schemes are defined as in Equations (2) and (3). The operation and maintenance cost $C_{t}$ are in our model deterministic and fixed costs, but in principle they can also be modelled as stochastic, if necessary. The interest bearing debt is calculated as follows: In the year of investment, a loan corresponding to a certain percentage of total investment $\Omega_{0}$ is taken, which is then repaid on an annuity basis over a predefined amount of years.

The liquidity management is addressed through creating a cash reserve, here denoted the liquidity reserve $L_{t}$, which changes with $\Delta L_{t}=L_{t}-L_{t-1}$. The liquidity reserve must not become negative at any point in time during the project lifetime. As soon as $L_{t}<0$, there is insufficient cash available and the firm experiences financial distress.

We calculate the free cash flow available for shareholders after liquidity management as:

$$
F C F E_{t}^{L M}=F C F E_{t}+\Delta L_{t}
$$

The change in liquidity reserve $\Delta L_{t}$ depends on the liquidity reserve still available in the ongoing year $L_{t}$, the expectation of $F C F E_{t+1}$ and the risk appetite of a firm. In order to determine the required level of liquidity reserve $L_{t}$ to avoid financial distress in the following year with sufficient probability, we apply a quantile computation analogous to the Value-at-Risk (VaR) calculation:

$$
\eta=Q_{1-\alpha}\left(F C F E_{t+1}\right)=\sup \left\{1-\alpha: P\left(F C F E_{t+1}<1-\alpha\right)\right\}
$$

where $\eta$ is the level exceeded by $F C F E_{t+1}$ at confidence level $\alpha \in(0,1)$. We define $L_{t}=\max \{0,-\eta\}$. If $\eta$ is positive, no liquidity reserve is required since the free cash flow is almost certainly positive and thus sufficient to satisfy all payment obligations. In contrast, a negative $\eta$ implies that liquidity reserves are necessary to prevent financial distress. 
We determine $\eta$ by Monte Carlo simulations on $F C F E_{t}$. Assuming for example that the firm strives to avoid financial distress with a probability of $\alpha=99.73 \%$ (the three-sigma rule), financial distress may only occur in $0.27 \%$ of the simulation paths in any year. From the simulation results, we determine $\eta$ as the $0.27 \%$-quantile of $F C F E_{t+1}$, from which we then derive the required liquidity reserve $L_{t}$. Depending on the level of the liquidity reserve in the previous year $L_{t-1}$, we subsequently determine the required change in reserve $\Delta L_{t}$.

After having determined the necessary liquidity reserve for each year, an additional set of Monte Carlo simulations must be undertaken for $F C F E_{t}^{L M}$. In outcomes where $F C F E_{t+1}$ realises as $F C F E_{t+1}>\eta$, the excess reserve is paid out to the shareholders in each year, so that no cash is held in the firm other than the reserve required for the subsequent year. In outcomes where the liquidity reserve was not sufficient in a year, i.e. where $F C F E_{t+1}$ realises as $F C F E_{t+1}<\eta$, the firm is assumed to immediately default. As a simplification we model this as if from this year onwards, all future cash flows in the defaulting simulation path become zero. This implies that we do not consider any final financial settlements and consider neither additional equity obligations nor pay-outs after bankruptcy of the firm.

\subsection{Model outputs: Shareholder Value and Support payments}

The Shareholder Value is then determined as:

$$
S H V=\sum_{t=0}^{T} \frac{F C F E_{t}^{L M}}{\left(1+r_{e}\right)^{t}}
$$

The free cash flows available for shareholders after liquidity management $F C F E_{t}^{L M}$ are discounted with the cost of equity $r_{e}$, which is described in Section 3.6

The support payments are determined differently for each support scheme:

For FIP schemes with a fixed market add-on, the support level is straightforward: It directly corresponds to the guaranteed premium. The net present value of support payments (NSP) is for each simulation path calculated as the sum of the discounted yearly support payments, which corresponds directly to the project revenues from support:

$$
N S P_{F I P}=\sum_{t=1}^{T} \frac{q_{t} F I P}{\left(1+r_{f}\right)^{t}}
$$

where we use the risk-free rate $r_{f}$ to reflect the social time preference rate, as the support payments are borne by society as a whole $\mathrm{I}^{2}$ This ensures also a consistent comparison of the different cases.

For FIT schemes, the support payments have to be determined as difference between the guaranteed tariff and the market price:

$$
N S P_{F I T}=\sum_{t=1}^{T} \frac{q_{t}\left(F I T-S_{t}\right)}{\left(1+r_{f}\right)^{t}}
$$

This relies on the following assumptions: (1) the market value of the electricity produced under the FIT corresponds to the current market price $S_{t}$, (2) this value is fully realised by the off-taking entity, and (3) the revenue from its market sales is entirely used to counterbalance the cost of support. Note that potentially, in years where the market price lies above the guaranteed price level, the FIT support costs can be below zero.

To obtain the equivalent FIT support level in real terms that is directly comparable with the FIP support level, the total support payments NSP FIT $_{I T}$ are then divided by the total production and an equivalent real per unit price is computed using an annuity factor.

Besides the expected values, the Monte Carlo simulations also allow us to determine a probability distribution for all model outputs.

\footnotetext{
${ }^{2}$ How societal risk preferences should be reflected in the used discounting factor requires further investigation. As the NSP serves subsequently only as a relative measure for comparing different support schemes, we leave this question for further research.
} 


\subsection{Estimating beta and the support scheme-specific cost of capital}

As mentioned above, we use the CAPM to describe the impact of systematic risk on the required return on equity. The expected rate of return on equity $r_{e}$ is estimated by the CAPM as (see Brealey and Myers, 2003):

$$
E\left[r_{e}\right]=r_{f}+\beta_{e}\left(r_{m}-r_{f}\right)
$$

where $r_{f}$ is the risk-free rate, $r_{m}$ is the market return, and $\beta_{e}$ is the equity beta.

The risk-free rate $r_{f}$ and the market return $r_{m}$ are general (not firm-specific) indicators and can be estimated by adequate long term government bonds and market indices (such as the S\&P500, Eurostoxx or DAX). The equity beta $\beta_{e}$ describes to what extent the risks of a firm (in occurrence a project) are correlated with general market risks.

Generally, $\beta_{e}$ is derived from historical observations using a two-step procedure: First, an asset beta $\beta_{a}$ is determined from historical returns (on shares) using Equation [19:

$$
\beta_{a}=\frac{\operatorname{Cov}\left(r_{a}, r_{m}\right)}{\operatorname{Var}\left(r_{m}\right)}
$$

This procedure can easily be applied for firms with publicly quoted stocks, using historical time series of their stock prices. However, we are not dealing with a stock-listed company but a specific investment project. We thus have to derive historical equivalent returns by creating a time series of profits for each support type. Since the price for FIT consists of a fixed tariff, there is no variation in returns. For FIP schemes, we create a time series from historical power prices, the fixed premium and a fixed level of operation and maintenance cost and depreciation. This reflects typical FIP 'profits', from which the returns can be derived. Using Equation (19), the asset beta $\beta_{a}$ can be derived, comparing the obtained time series to the market index. Since the FIP time series becomes more or less volatile depending on the level of the fixed premium, the asset beta changes with the support level granted. This should be accounted for in any model application.

Second, the $\beta_{a}$ needs to be re-leveraged to $\beta_{e}$ based on specific firm characteristics, i.e. the debt/equity-ratio $\frac{D}{E}$ and the tax rate $r_{T}$, using Equation 20, (Koller et al. 2010 p.713):

$$
\beta_{e}=\beta_{a}\left(1+\left(1-r_{T}\right) \frac{D}{E}\right)
$$

The resulting 'geared' beta $\beta_{e}$ can be used to calculate the cost of equity using Equation 18 .

For the data analysis, we use the closing price of each trading day from a (stock) market index and compare it to a closing price of forward electricity prices, which are then adjusted according to the support scheme. Here, closing prices of short term electricity forwards (e.g. one-year ahead) are used as basis, acknowledging that the life-time value of a project does not only depend on short term electricity forwards, but on the longer term electricity price evolution. Yet data and our empirical estimation of the power price model suggest that one-year ahead power futures already strongly correlate with the long-term price expectations. Therefore, changes in forward prices reflect changes in project value and can be compared to asset prices from stock markets.

\section{CASE APPLICATION: OFFSHORE WIND PROJECT}

Applying the developed model to a specific case, we chose an exemplary offshore wind project in the German Baltic Sea. We first introduce the assumptions taken for the cash flow analysis, then proceed to the beta analysis, and finally present the case results.

\subsection{Cash flow analysis}

As basis for the cash flow analysis, we make a number of assumptions related to the specific implementations of the support schemes, the stochastic processes, and project specific characteristics. 


\subsubsection{Support schemes}

As mentioned in Section 11. feed-in tariffs and premiums are the two support schemes that are highly relevant in the current European discussion of energy policy development. We thus compare the two in our case.

We assume the FIT scheme to be a traditional price guarantee. This means that an operator of a renewable project receives a pre-determined, fixed price for each unit of electricity generated, independent of the market price. We do not allow temporary or permanent opting-out of the FIT scheme. We see this as simplification, as in some circumstances an opting-out might be attractive, e.g. when the market price becomes structurally higher than the guaranteed tariff. Such analysis is not in focus of our study, but it might be relevant for future investigation.

We assume the FIP scheme to be a pre-determined, fixed add-on to the market price for each unit of electricity generated. Neither the FIT nor the FIP prices are assumed to be index-regulated, i.e. they do not increase with inflation, but remain constant in nominal terms. In order to increase the transparency of results, we assume that the support in both cases is granted throughout the project lifetime. We do not ex ante assume a support level. We rather determine the minimum required support levels in each scheme as an output measure.

\subsubsection{Calibration of the price processes}

The two-factor Schwartz and Smith model is calibrated to the German power market. As basis for the calibration, we use German power forwards (Phelix Futures), more specifically the closing price on each trading day between October 2003 and September 2013 (EEX, 2014). The relevant prices of the 1-year Forwards and 5-year Forwards are shown in Figure 2 Since the focus of the paper is not on advanced econometric estimation, we use rather straightforward calibration techniques for deriving the parameter values.

For the long term process, the drift and volatility parameters $\mu_{\xi}$ and $\sigma_{\xi}$ have to be estimated. We use 5-year Forwards as proxy, since these represent the longest time horizon on the German power market with at least some trading volume on a continuous basis. $\sigma_{\xi}$ is estimated as the standard deviation of price differences $\Delta \xi_{t}=\ln \left(\bar{S}_{t}\right)-\ln \left(\bar{S}_{t-1}\right)$, where $\bar{S}_{t}$ is represented by the weekly time series of the 5-year Forward over ten years (from mid 2003 to mid 2013). The drift $\left(\mu_{\xi}+\frac{1}{2} \sigma_{\xi}^{2}\right)$ is estimated by taking the average of $\Delta \xi_{t}=\ln \left(\bar{S}_{t}\right)-\ln \left(\bar{S}_{t-1}\right)$, and hence $\mu_{\xi}$ can be analytically derived from the formula. In a last step, the parameters must be annualised from weekly values using a factor of $\sqrt{\Delta t}$, whereby $\Delta t=1 / 52$. We arrive at an annual drift of $\mu_{\xi}=0.00148$ and volatility of $\sigma_{\xi}=0.11402$. As starting value $\bar{S}_{0}$ for the simulation, we take the closing price of the last traded 5-year Forward of our time series, i.e. from week 36 in 2013, and obtain $\bar{S}_{0}=37.65$ EUR/MWh.

For the short term process, the mean reversion coefficient $\kappa$, the volatility parameter $\sigma_{\chi}$ and correlation parameter $\rho_{\xi \chi}$ have to be estimated. We estimate the mean reversion coefficient $\kappa$ from an ordinary least squares regression analysis of the time series $\Delta \chi_{t}=\chi_{t}-\chi_{t-1}$ with $\chi_{t-1}=\ln \left(S_{t-1}\right)-\xi_{t-1}$. From the resulting weekly coefficient $\alpha$, the annualised mean reversion rate is derived using the relation $-\ln (1+\alpha) / \Delta t$ (cf. Equation $(10)$ ). We obtain $\kappa=0.5377$. In an alternative approach based on Skorodumov (2008) that uses the property of half-life of a mean-reverting process $t_{1 / 2}=\ln (2) / \alpha$ for estimating the mean reversion and a graphical analysis of the price process, we would arrive at a similar level of $\kappa=0.4806$. We derive volatility $\sigma_{\chi}$ by making use of the closed-form solution of the process, as described by $\operatorname{Davis}(2012)$ :

$$
\operatorname{Var}\left[\chi_{t+\Delta t}\right]=\left(1-e^{-2 \kappa(t+\Delta t)}\right) \frac{\sigma_{\chi}^{2}}{2 \kappa}
$$

We estimate $\operatorname{Var}\left[\chi_{t+\Delta t}\right]$ from our time series through least squares linear regression. Inserting all parameters into Equation 21), we find the volatility of the short term process to be $\sigma_{\chi}=0.0976$. To estimate correlation $\rho_{\xi \chi}$, we apply the standard statistical approach, using $\rho_{\xi \chi}=\left(\sum_{i=1}^{n}\left(\Delta \xi_{i}-\Delta \bar{\xi}\right)\left(\Delta \chi_{i}-\Delta \bar{\chi}\right) /\left((n-1) \sigma_{\xi} \sigma_{\chi}\right)\right.$, where we have $n=520$ observations. The correlation is estimated to be $\rho_{\xi \chi}=0.1073$. As starting value $S_{0}$ for the simulation, we take the closing price of the last traded 1-year Forward of our time series, and obtain $S_{0}=37.28$ EUR/MWh.

\subsubsection{Calibration of the wind distribution}

The wind model is calibrated to a historical wind index. The most comprehensive set of data available is from Denmark (EMD 2013), which is a set of monthly values from 1979 to 2013. Since our model is based on annual considerations, we aggregate the data into yearly values. We assume that this data set is also applicable for a location in the German Baltic Sea.

As described in Section 3.3 the Weibull distribution is determined by scale parameter $\lambda$ and shape parameter $k$. We use the maximum likelihood method for estimating the parameters, and obtain $\lambda=103.6$ and $k=12.05$. The wind index obtained from the Weibull distribution is then multiplied with the expected annual wind production. 

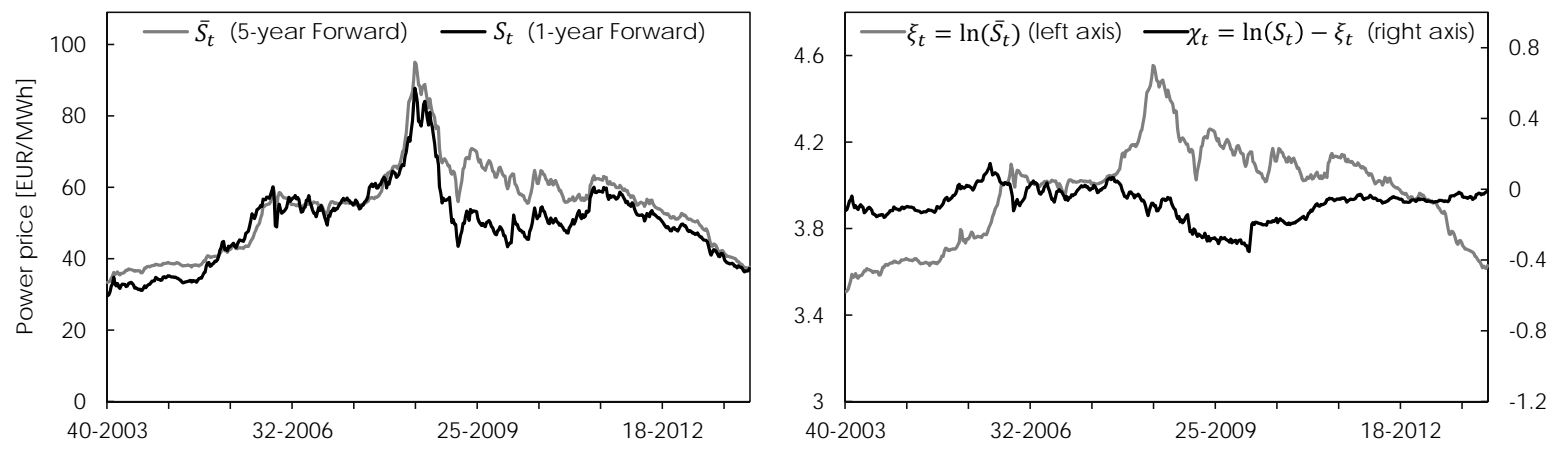

Fig. 2: Historical power prices, weekly, 1-year and 5-year Forwards from the German market (EEX), and the corresponding short-term and long term model processes
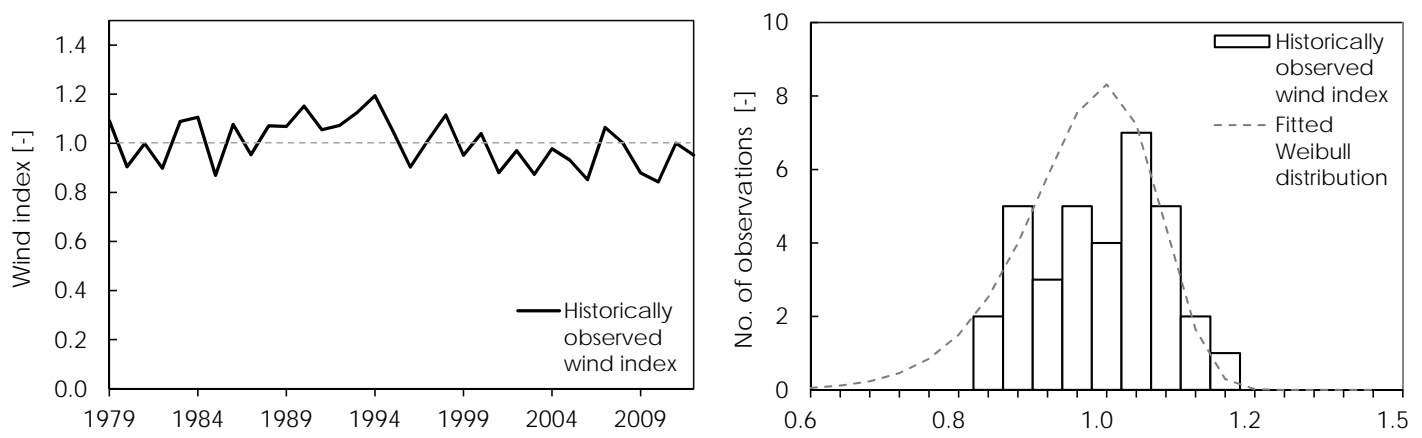

Fig. 3: Historical wind production index, annual, 1979-2013 (EMD 2013), and the fitted Weibull distribution

We estimate the expected annual wind production to be $4,040 \mathrm{MWh} / \mathrm{MW}$ at $100 \%$ availability, which is the expected average for a typical new large offshore wind park in the Baltic Sea, such as Kriegers Flak (DEA 2012). At 96\% availability, the expected electricity exported to the grid is estimated at 3,878 MWh/MW per year.

\subsubsection{Project specific cost assumptions}

The required project specific assumptions are investment cost, operational cost, project lifetime, depreciation rules, and income tax rate. Table 1 summarises all estimates.

Table 1. Project specific cost assumptions, based on 4C Offshore Limited (2013), PwC (2012), KPMG (2010), DEA (2012), and own calculations

\begin{tabular}{lr}
\hline Investment cost & $3.01 \mathrm{mEUR} / \mathrm{MW}$ \\
Additional financing cost & $0.86 \mathrm{mEUR} / \mathrm{MW}$ \\
Operational cost & $106.8 \mathrm{kEUR} / \mathrm{MW} / \mathrm{y}$ \\
Lifetime & 20 years \\
Depreciation & straight line, 20 years \\
Income tax rate & $28.1 \%$ \\
\hline
\end{tabular}

We estimate investment costs based on an average of the historical investment cost of all 45 commercial offshore wind parks in Europe (data collected from 4C Offshore Limited 2013). Furthermore, we expect additional project financing cost, which we estimate based on information given in $\mathrm{PwC}(2012)$. Total upfront capital expenditures are thus estimated to be 3.87 million EUR/MW

Empirical values for operational costs of offshore wind parks in Europe range from 20.2 EUR/MWh to 36.7 EUR/MWh (2010 prices) (KPMG, 2010, p.80). In reality, the operational cost are partially fixed and partially dependent on the production 
volume. We simplify by assuming fixed annual cost. We use the average value of KPMG (2010) transferred to 2014-prices and a per-MW-value, arriving at a fixed annual cost of $106.8 \mathrm{kEUR} / \mathrm{MW}$.

The income tax rate in Germany comprises $15 \%$ corporate tax, $0.825 \%$ solidarity levy, and a local trade tax, which depends on the municipality the offshore wind park is assigned to. The federal State of Schleswig-Holstein e.g. suggests that local trade tax from offshore wind parks is to be paid out to the municipality of Helgoland (Ropohl. 2010), with a local tax rate of $12.25 \%$. In total, we arrive at an income tax rate of $28.1 \%$.

\subsubsection{Assumptions on debt financing cost}

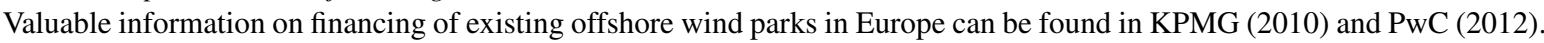

In Table 2, we present some relevant data for the (rather limited) experiences in Germany.

Table 2. Financial data of real offshore wind parks in Germany $\mathrm{PwC} 2012$ p.73)

\begin{tabular}{llccccc}
\hline $\begin{array}{c}\text { Financial } \\
\text { Close }\end{array}$ & Project & $\begin{array}{c}\text { Capacity } \\
\text { (MW) }\end{array}$ & $\begin{array}{c}\text { Cost } \\
\text { (mEUR) }\end{array}$ & $\begin{array}{c}\text { Gearing } \\
\text { (Debt share) }\end{array}$ & $\begin{array}{c}\text { Tenor (Loan } \\
\text { maturity) (years) }\end{array}$ & Margin \\
\hline 2011 & Globaltech 1 & 400 & 1850 & $58 \%$ & 15 & $3 \%$ \\
2011 & Meerwind & 288 & 1200 & $69 \%$ & 15 & $2.5-3 \%$ \\
2010 & Borkum West & 200 & 780 & $59 \%$ & $2+15$ & $i 3 \%$ \\
\hline
\end{tabular}

From the data of existing German projects, we can expect a debt share between $60 \%$ and $70 \%$. Since this is such a decisive assumption for the case, we analyse different debt shares within this range.

We assume that the project can obtain a 15 -year loan. The total interest rate consists of a bank margin (2.5\% to $\measuredangle 3 \%)$, added to a (risk-free) reference rate. As reference rate, the interest rates for 10-year German government bonds can be used The 'Bund 14' was at $1.66 \%$ in January 2014 (Bundesbank 2014). Often, a swap premium is also added (typically $0.2 \%$ to $0.5 \%$ ) (PwC 2012). We hence estimate the total interest rate to be $5.21 \%$, consisting of $1.66 \%$ reference rate, $3.25 \%$ margin and $0.3 \%$ swap premium.

\subsection{Beta analysis and cost of equity}

As described in Section 3.6 we start the beta analysis by determining the asset beta. We undertake the analysis based on historical developments of the DAX index (Bloomberg, 2014), as compared to returns composed of support payments and German one-year power forwards (Phelix Futures) (EEX 2014). Annual costs are deducted from the returns, as described above. We have ten years of consistent data, from October 2003 to September 2013, with data on each trading day. Power price data before 2003 are not considered as being sufficiently reliable because of limited market liquidity in the first years after liberalisation.

From time series analysis, we find a positive correlation of the market index and the power prices. A FIT scheme, which eliminates this positive correlation through a fixed price guarantee, is expected to have an asset beta of zero. This can certainly be seen as a simplification, but is theoretically consistent in our approach. A FIP scheme partially decreases the positive correlation, to an amount depending on the support level: The higher the support level, and thus the fixed part of the income, the lower the correlation of return with the market. Figure 4 shows the results of our analysis.

Depending on the support level, we are now able to determine the beta, using the relationship depicted in Figure 4 In order to estimate the equity beta $\beta_{e}$, we re-leverage the betas using Equation 20, specifically for each support level. For example, a FIP of 50 EUR/MWh corresponds to approximately $150 \%$ of the long-term average market price. The asset beta amounts to $\beta_{a}=0.11$ and the corresponding equity beta is then $\beta_{e}=0.24$, with $28.1 \%$ tax rate and $60 \%$ debt share.

The results of our analysis correspond roughly to the findings of $\mathrm{PwC}(2012)$, who estimate that the introduction of a FIT mechanism in the UK will result in a 0.1 reduction of the asset beta.

We obtain the overall cost of equity by applying Equation (18). Here, we make a restriction: We assume that the cost of equity applied in the project appraisal cannot be lower than the total interest rate of the loan obtained for the project plus a margin. This reflects rational decision making by shareholders who would not accept a lower expected rate of return for their

\footnotetext{
3 German government bonds with 15 year duration are rather exceptional. Therefore 10-year bonds are used as best available approximation.
} 


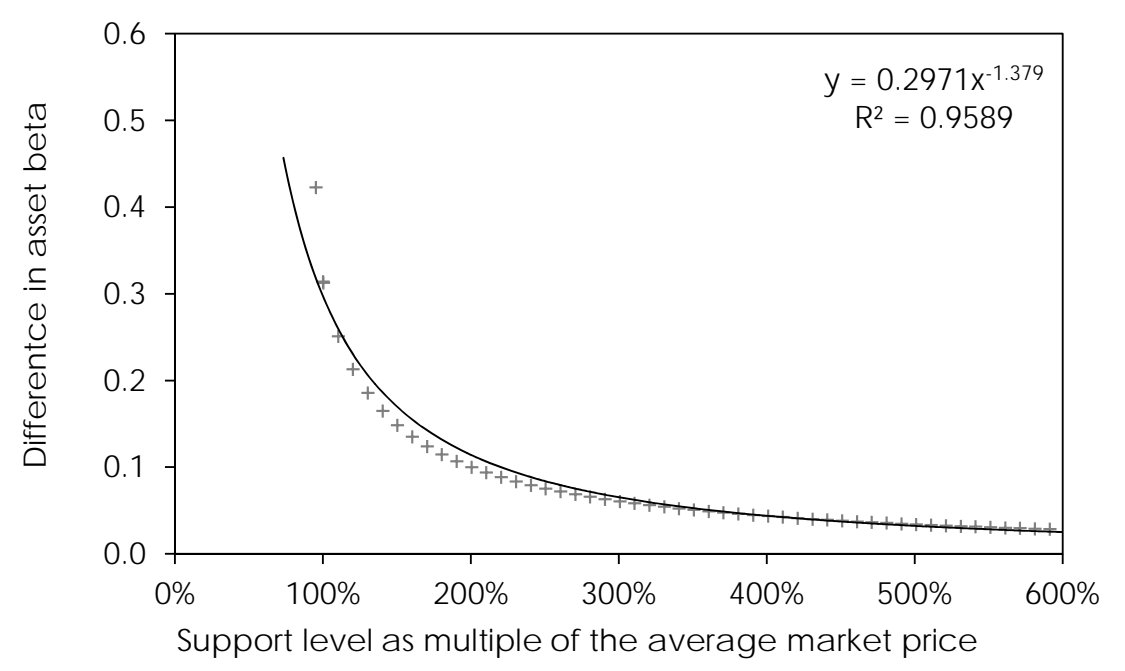

Fig. 4: Difference in asset beta of a FIP scheme as compared to a FIT scheme

equity than the cost of debt. In fact, as the equity in a project involves greater risks than the debt, there should be a positive margin between the cost of equity and the cost of debt. We estimate this margin to be $2 \%$, which is a conservative assumption when compared to Wallasch et al. (2011, p.99) and $\mathrm{PwC}$ (2012) where differences between cost of equity and cost debt amount $4-7 \%$.

\subsection{Results of the case application}

In order to test the significance of liquidity management for the results, we first analyse the case for a situation, in which no liquidity management is undertaken (Section 4.3.1. Here, we assume that the firm can tolerate negative cash holdings, e.g. through a bank agreement with short term loans or through a mother company guarantee. Subsequently, we analyse the same case including liquidity management (Section 4.3.2.

The support levels are set so that in each case, a Shareholder Value of zero is reached, which is assumed to be the threshold of investment.

We show results for both a $60 \%$ debt share and a $70 \%$ debt share. We do this, because the assumption on debt share is, while rather uncertain, decisive for the results. Moreover, one could expect that the FIT can achieve higher debt shares than a FIP, because of the more stable cash flows. We thus also calculate a case where the FIT has a debt share of $70 \%$ while the FIP has a debt share of $60 \%$.

\subsubsection{Results without liquidity management}

Having applied the model described above, we arrive at the following results in case the firm would not undertake any liquidity management. Table 3 summarises all results for the undertaken variations in debt share.

Table 3. Case results without liquidity management: Required support levels and their differences for three cases of debt shares

\begin{tabular}{lcc|cc|cc} 
& FIT & FIP & FIT & FIP & FIT & FIP \\
\hline Debt share & $60 \%$ & $60 \%$ & $70 \%$ & $70 \%$ & $70 \%$ & $60 \%$ \\
\hline & $E U R / M W h$ & \multicolumn{2}{|c|}{$E U R / M W h$} & \multicolumn{2}{|c|}{$E U R / M W h$} \\
Tariff / Premium & 123.5 & 87.3 & 121.2 & 85.4 & 121.2 & 87.3 \\
Equivalent support level & 83.1 & 87.3 & 80.7 & 85.4 & 80.7 & 87.3 \\
\hline Difference in support level & \multicolumn{2}{c|}{4.2} & \multicolumn{2}{|c|}{4.7} & \multicolumn{2}{|c}{6.6}
\end{tabular}

The equivalent support levels of the FIT scheme are determined as described in section 3.5 The support levels required to reach a Shareholder Value of zero differ between the FIT and the FIP scheme by 4.2 to 6.6 EUR/MWh, corresponding to 5-8\% 
of total support. Figure 5 shows the corresponding distributions of SHV and support payments for the third presented case. Obviously, the variation in shareholder value across the simulations is much higher in case of an FIP, whereas the variations in support payments are stronger for the FIT scheme.
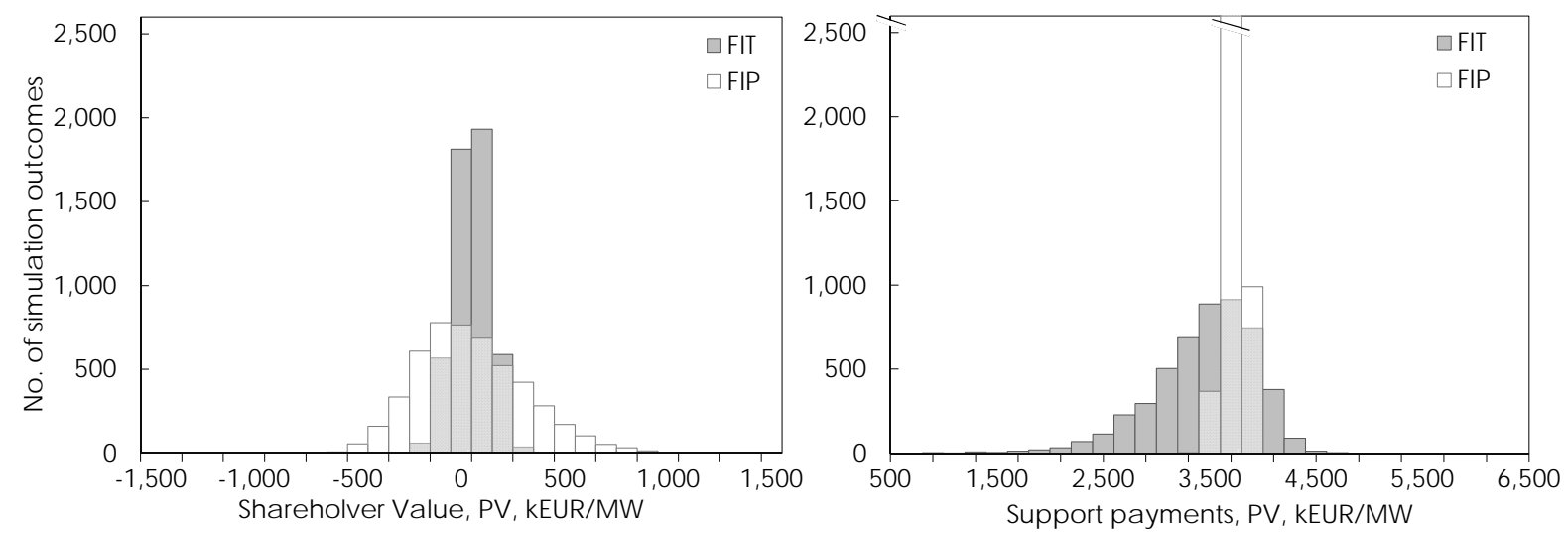

Fig. 5: Case results without liquidity management, for debt shares of 70\% (FIT) and 60\% (FIP), respectively

The overall results are in line with the results of Kitzing (2014) who, based on a mean-variance approach, calculates a difference of 5-10 EUR/MWh between FIT and FIP, depending on the size of the support paid.

\subsubsection{Results with liquidity management}

To capture more of the unsystematic risk in a theoretically consistent approach, we have introduced liquidity management in the firm, as described in Section 3.4 Table 4 summarises all results from the related case calculations.

Table 4. Case results with liquidity management: Required support levels and their differences for three cases of debt shares

\begin{tabular}{lcc|cc|cc} 
& FIT & FIP & FIT & FIP & FIT & FIP \\
\hline Debt share & $60 \%$ & $60 \%$ & $70 \%$ & $70 \%$ & $70 \%$ & $60 \%$ \\
\hline & $E U R / M W h$ & \multicolumn{2}{c|}{$E U R / M W h$} & \multicolumn{2}{|c|}{$E U R / M W h$} \\
Tariff / Premium & 125.3 & 89.1 & 123.6 & 88.0 & 123.6 & 89.1 \\
Equivalent support level & 84.9 & 89.1 & 83.2 & 88.0 & 83.2 & 89.1 \\
\hline Difference & \multicolumn{2}{c|}{4.3} & \multicolumn{2}{|c|}{4.8} & \multicolumn{2}{|c}{5.9}
\end{tabular}

As expected, higher support levels are required than in the case without liquidity management, between 1.8 and 2.6 EUR/MWh. This is due to the cost related to holding the liquidity reserves. In our scenarios, the highest liquidity reserves are necessary under the FIP scheme with $70 \%$ debt share, where the cost of holding the reserve has a present value of 88 kEUR/MW, which corresponds to 53 million EUR for a wind park with $600 \mathrm{MW}$. In the same case, the FIT scheme would cause 4 million EUR less in liquidity reserves. Naturally, the cost of liquidity reserves are highest at high debt shares, as the increased debt service reduces the cash flows to shareholders.

The difference in support levels required to reach a Shareholder Value of zero now lies between 4.3 and 5.9 EUR/MWh, corresponding to 5-7\% of the total support. Figure 6 shows the resulting distributions for the third presented case, in which the debt shares differ.

For the first two cases, where debt shares are the same (60\% and $70 \%$ for both schemes), the difference in required support level has slightly increased (by approx. 2\%). This difference seems rather small at first. This is, however, due to another opposing effect: the higher support level stabilises the income from FIP as compared to the case without liquidity management, because now a smaller part of the income stems from the market and a larger part of the income is fixed. The FIP payment now makes $81 \%$ of the overall income, rather than $80 \%$ as before. The difference is only $1 \%$-point, but it changes the profile significantly. Due to the higher fixed share in income, the beta is reduced (see the relationship depicted in Figure 4), and thus the difference in cost of capital between the two schemes decreases. The reduced beta works in favour of the FIP scheme, whereas the liquidity management does the opposite. 

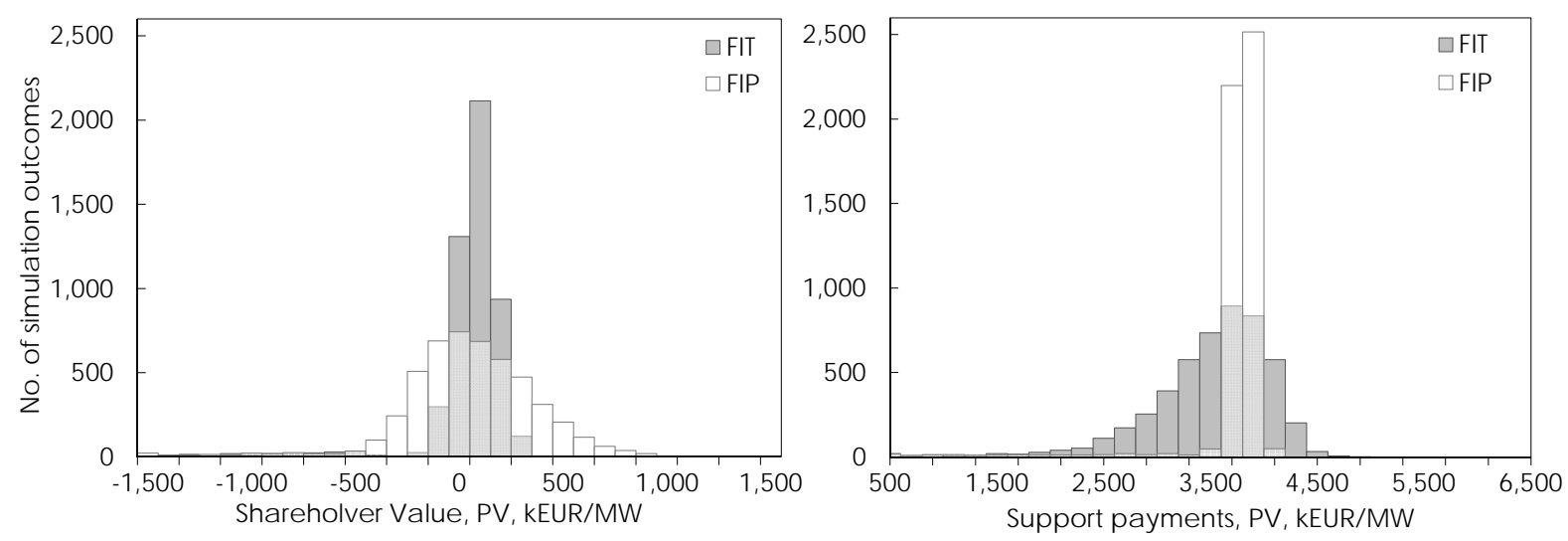

Fig. 6: Case results with liquidity management, for debt shares of 70\% (FIT) and 60\% (FIP), respectively

The numbers from the 70\%-debt-share-case may illustrate this point: Because of the higher support level required from introducing liquidity management, the average equity beta decreases from 0.217 to 0.208 . Without this decrease in beta, the difference in support levels between the FIT and the FIP scheme would actually have increased even more, to 5.0 EUR/MWh. This was however overshadowed by the effect from the beta reduction before.

In the third case, where the FIT has a debt share of $70 \%$ and the FIP a debt share of $60 \%$, the difference between the required support levels is actually reduced when considering liquidity management. This is due to the fact that here, the FIT needs comparably more liquidity reserves than the FIP, because of the higher debt share and the related lower cash flows available to shareholders.

Overall, we can conclude that in our investigated cases, most of the difference in support level stems from systematic risk, modelled through the beta differences. The addition of liquidity management is less significant, but it can be an important part of the analysis, as it counterbalances some reduction effects from changes in beta that could otherwise have led to an underestimation of the differences in required support level.

\section{DISCUSSION}

\subsection{Comparison to the actual EEG tariffs}

The German Renewable Energies Act (EEG) provides two different options of feed-in tariffs for offshore wind parks starting operation before January 2018:

1. An initial tariff of $150 \mathrm{EUR} / \mathrm{MWh}$ for 12 years plus a tariff of $35 \mathrm{EUR} / \mathrm{MWh}$ for the remaining 8 years;

2. An initial tariff of 190 EUR/MWh for 8 years ('optional acceleration model') plus a tariff of 35 EUR/MWh for the remaining 12 years.

The period for the initial tariff of $150 \mathrm{EUR} / \mathrm{MWh}$ is extended by 0.5 months for every nautical mile of distance to shore outside the 12-mile zone, and by 1.7 months for each metre of water depth exceeding 20 metres. We estimate that a park with a distance to shore and water depth typical for German offshore wind parks currently under development could realistically achieve 14 years of the higher initial tariff of $150 \mathrm{EUR} / \mathrm{MWh}$, and then 6 years at $35 \mathrm{EUR} / \mathrm{MWh}$.

Applying these tariff levels in our model, we obtain an internal rate of return for the project of $6.4 \%$, which is in line with the rates of return of 7-9\% that the German government assumes reasonable for wind parks (at somewhat higher assumptions on cost of debt) (see Wallasch et al. 2011). Hence, our model overall aligns with what is underlying official government policy in Germany.

In a next validation step, we compare the EEG tariff levels to our calculated ones, using the indicator of discounted net support payments over the whole lifetime of the project. These amount to 3.7 million EUR/MW for the EEG tariffs as compared to 3.4 to 3.5 million EUR/MW in our cases. We thus arrive at support payments that are equivalent to 92-95\% of the actual EEG 
levels. Hence, our modelled tariffs of 121.2 to $125.3 \mathrm{EUR} / \mathrm{MWh}$ (that are assumed constant over 20 years) are comparable to the actual EEG tariffs (that are stepping down from 150 to 35 EUR/MWh after the initial period).

\subsection{Model assumptions and their consequences}

We assume for transparency reasons and comparability of results that there is no opt-out option of the feed-in tariff scheme. However, we can see from the simulations in the case that in $4.7 \%$ of the price scenarios, a price occurs exceeding the lowest FIT level (of 121.2 EUR/MWh). In these situations, a RES-E producer would opt out of the FIT scheme and transfer into normal market operation had he the opportunity to do so. This has some consequences on our estimation of support payments, as they are estimated as the difference between guaranteed tariff and market price and can become negative. Had the FIT producer the option to leave the FIT scheme whenever the market price exceeds the tariff (and maybe even return to the FIT at a later point in time), no instances of negative support payments could occur. In this case, the netting approach adopted here would underestimate the overall support payments related to a FIT.

Assumptions regarding project-specific costs are also decisive for the results. We have used average values for all estimations. Specific parks can lie significantly higher or lower than that. This will have an effect on the required support levels and also on the absolute differences. However, since support schemes are usually not designed for single projects but a whole sector, our approach of taking an average wind park seems reasonable. Additionally, it could also be beneficial to test the consequences for a marginal park, i.e. the most expensive wind energy investment necessary to reach deployment targets.

The choice of power price process and its calibration also affects the results. Especially seasonal variations and jumps could have been modelled. However, we do not expect that incorporating these into the model would lead to significant changes in the comparative conclusions, because of the long time horizon of the analysis. We have confirmed that moderate changes in parameters of the short term process do not have any significant effect on the conclusions.

An issue still to be analysed is what the consequences are of having two different distribution types. The wind production model uses a Weibull distribution, whereas the power prices are assumed lognormal. Since the cash flows under the FIT scheme only depend on the wind production and not the power prices, the results under the two support schemes FIT and FIP are affected differently by the two distribution types. Especially the skewness factor differs between the two schemes. Whether this affects the comparison of the support schemes depends on the risk preferences of the decision makers. Here, further investigations are needed.

\subsection{Implications for policy makers}

The model and insights generated in this study can help policy makers to determine appropriate support levels for renewable support schemes. This is especially relevant when switching from FIT to FIP schemes. Then, the support levels of the FIT cannot be directly transferred to the new scheme - they must be adjusted upwards to ensure continued adequacy of investment incentives.

In the recent past, policy makers in Europe are becoming more and more concerned with the burden of support schemes on consumers (Del Río and Cerdá 2014). Policy making strives to limit total support costs to a minimum that can still provide the desired deployment of new renewable projects. In this, policy makers should be aware of the connection between required support level and risk exposure: The higher the risk exposure, the higher the required support level. As this analysis illustrates with a quantitative case, the effect of both systematic risk and unsystematic risk should not be neglected in policy making.

\subsection{Further development of the approach}

In a first step, it could be beneficial to test the significance of several assumptions made. First, the loan maturity could influence the results significantly. We expect that the shorter the duration of the loan, the smaller the difference between the support schemes. Second, with technology development and further decreases in overall cost of offshore wind, also the support levels are expected to decrease. It could thus be beneficial to make a similar analysis with reduced support levels. We expect that the lower the support levels are, the larger the difference between the FIT and FIP scheme becomes, as volatile market prices become more dominant in the FIP case.

As the results are very sensitive to the assumed debt share, it would be of great advantage if these were not set exogenously, but could be determined endogenously. This could be e.g. done on on the basis of probabilistic analysis of deficits in debt 
service, and limiting them to a certain level. We expect that here, the FIT could achieve higher debt shares, due to the more stable income flows.

Additionally, the model could be further expanded to cover other support instruments, such as tradable green certificate systems with quotas.

\section{CONCLUSION}

This study contributes to the analysis of risk implications from policy instruments in several ways: First, we developed a multiyear approach to liquidity management in a firm in order to capture effects of exposure to unsystematic risks. Second, we adapted the framework to wind energy investment projects. Third, we quantified the policy consequences of choosing between feed-in tariffs and premiums for a specific case.

In an application case for a German offshore wind park in the Baltic Sea, we estimated that a FIP scheme would require 4.3 to 5.9 EUR/MWh higher support level in order to give the same investment incentive as a comparable FIT. This corresponds to about $5-7 \%$ of the total support payments. At the same time, the risk distribution both for investors and support payers is changed strongly.

Such risk implications should be taken into consideration when support policies are chosen and the respective support levels are determined. Otherwise, support levels might not be set at an adequate level, and the investment incentives experienced on the market could be quite different than what was intended by policy makers. This could lead to under-investment on the one hand, so that RES-E targets may not be achieved, or to over-investment on the other, so that total support cost are not easily predicted or controlled.

\section{ACKNOWLEDGEMENTS}

This study is undertaken as part of the ENSYMORA project (Energy systems modelling, research and analysis) with gratefully acknowledged funding by the Danish Council for Strategic Research.

\section{REFERENCES}

4C Offshore Limited, 2013. Global offshore wind farms database. Technical Report. Website, www.4coffshore.com/windfarms/.

Acharya, V., Almeida, H., Campello, M., 2007. Is cash negative debt? A hedging perspective on corporate financial policies. Journal of Financial Intermediation 16, 515-54.

Arrow, K.J., 1965. The theory of risk aversion, in: Arrow, K.J. (Ed.), Reprinted in: Essays in the theory of risk-bearing, 1971. Markham Publ.

Bates, T.W., Kahle, K.M., Stulz, R.M., 2009. Why Do U.S. Firms Hold So Much More Cash than They Used To ? The Journal of Finance LXIV, 1985-2021.

Bloomberg, 2014. Deutsche Boerse AG German Stock Index DAX. Technical Report. Bloomberg L.P. Website, www.bloomberg.com/quote/DAX:IND.

Brealey, R.A., Myers, S.C., 2003. Principles of corporate finance. McGraw-Hill, New York City. 7th edition.

Bris, A., Welch, I., Zhu, N., 2006. The Costs of Bankruptcy: Chapter 7 Liquidation versus Chapter 11 Reorganization. The Journal of Finance LXI, 1253-303.

Bundesbank, 2014. Rates and yields of listed German government bonds (Kurse und Renditen börsennotierter Bundeswertpapiere) - January 2014. Technical Report. Deutsche Bundesbank.

Carta, J.A., Velázquez, S., 2011. A new probabilistic method to estimate the long-term wind speed characteristics at a potential wind energy conversion site. Energy 36, 2671-85.

Davis, G.A., 2012. Technical Note: Simulating the Two-Factor Schwartz and Smith Model of Commodity Prices. The Engineering Economist 57, 130-40.

Davydenko, S.A., 2012. Insolvency, Illiquidity, and the Risk of Default. Technical Report November. Working Paper. Joseph L. Rotman School of Management, University of Toronto.

DEA, 2012. Energy Policy in Denmark. Technical Report December. Governmental Report. Danish Energy Agency (Energistyrelsen). Copenhagen, Denmark. 
Del Río, P., Cerdá, E., 2014. The policy implications of the different interpretations of the cost-effectiveness of renewable electricity support. Energy Policy 64, 364-72.

EEX, 2014. Phelix Future market data. Technical Report. European Energy Exchange (EEX). Website, www.eex.com.

EMD, 2013. Wind energy index for denmark - monthly statistics 1979-2013. Technical Report. EMD International A/S. Website, www.vindstat.dk.

Fama, E.F., French, K.R., 1993. Common risk factors in the returns on stocks and bonds. Journal of Financial Economics 33 , 3-56.

Fama, E.F., French, K.R., 1997. Industry costs of equity. Journal of Financial Economics 43, 153-93.

Flannery, M.J., Lockhart, G.B., 2009. Credit lines and the substitutability of cash and debt. Technical Report 402. Working Paper. University of Florida.

Gross, R., Blyth, W., Heptonstall, P., 2010. Risks, revenues and investment in electricity generation: Why policy needs to look beyond costs. Energy Economics 32, 796-804.

Kitzing, L., 2014. Risk implications of renewable support instruments: Comparative analysis of feed-in tariffs and premiums using a mean-variance approach. Energy 64, 495-505.

Kitzing, L., Mitchell, C., Morthorst, P.E., 2012. Renewable energy policies in Europe: Converging or diverging? Energy Policy 51, 192-201.

Klessmann, C., Nabe, C., Burges, K., 2008. Pros and cons of exposing renewables to electricity market risksA comparison of the market integration approaches in Germany, Spain, and the UK. Energy Policy 36, 3646-61.

Koller, T., Goedhart, M.H., Wessels, D., 2010. Valuation: measuring and managing the value of companies. John Wiley and Sons Inc., Hoboken, NJ. 5th edition.

KPMG, 2010. Offshore Wind in Europe 2010 Market Report. Technical Report. KPMG.

Lintner, J., 1965. The Valuation of Risk Assets and the Selection of Risky Investments in Stock Portfolios and Capital Budgets. The Review of Economics and Statistics 47, 13-37.

Markowitz, H.M., 1952. Portfolio Selection. The Journal of Finance 7, 77-91.

Mossin, J., 1966. Equilibrium in a capital asset market. Econometrica: Journal of the Econometric Society 34, 768-83.

Phillips, P., 1972. The Structural Estimation of a Stochastic Differential Equation System. Econometrica 40, 1021-41.

PwC, 2012. Offshore wind cost reduction pathways study - Finance work stream. Technical Report April. PricewaterhouseCoopers LLP.

Ropohl, F., 2010. Let's talk about tax - Does taxation influence the planning of offshore wind parks?, in: GL Offshore Wind conference 2010, Ernst and Young.

Schaeffler, S., Weber, C., 2013. The Cost of Equity of Network Operators - Empirical Evidence and Regulatory Practice. Competition and Regulation in Network Industries 14, 385-411.

Schober, D., Schäffler, S., Weber, C., 2014. Idiosyncratic risk and the cost of capital: The case of electricity networks. Technical Report. ZEW Discussion Papers, No. 14-010. Zentrum für Europäische Wirtschaftsforschung / Center for European Economic Research.

Schwartz, E.S., Smith, J., 2000. Short-term variations and long-term dynamics in commodity prices. Management Science 46, 893-911.

Sharpe, W.F., 1964. Capital Asset Prices: A Theory of Market Equilibrium under Conditions of Risk. The Journal of Finance $19,425-42$.

Skorodumov, B., 2008. Estimation of mean reversion in Oil and Gas markets. Technical Report 1. Technical Report: MITSUI/2008-10-14. Mitsui and Co. Energy Risk Management Ltd.

Villanueva, D., Feijóo, A., 2010. Wind power distributions: A review of their applications. Renewable and Sustainable Energy Reviews 14, 1490-5.

Wallasch, A.K., Rehfeldt, K., Wallasch, J., 2011. Vorbereitung und Begleitung der Erstellung des Erfahrungsberichtes 2011 gemäß 65 EEG Vorhaben IIe Windenergie Endbericht. Technical Report. Deutsche WindGuard GmbH and Bio Consult SH. Varel, Germany. 